\title{
A dor forasteira e o belo passageiro: perspectivas nietzschiana e freudiana'
}

\author{
Maria Isabel de Andrade Fortes* \\ Pontificia Universidade Católica do Rio de Janeiro, Departamento de Psicologia. Rio de Janeiro, RJ, Brasil
}

Resumo: $\mathrm{O}$ artigo desenvolve a ideia de que a experiência do Belo inclui necessariamente a dimensão da dor, a partir das obras de Freud e de Nietzsche. No primeiro autor, investigam-se a dor da antecipação do luto em face da transitoriedade da beleza, a importância do conceito de sublimação e a análise sobre a experiência perturbadora de Freud diante da estátua de Moisés, de Michelangelo. No segundo, apresentam-se as principais ideias do livro 0 Nascimento da tragédia para demonstrar como a arte possui o poder de transformar o vazio em vitalidade, pois o sublime desloca a náusea e o horror da existência em representações com as quais é possível viver. Por isso, defende-se que o trágico supõe uma estética próxima do feio e do dissonante, fazendo do Belo uma experiência que inclui as dimensões da dor e do horror.

Palavras-chave: dor, Belo, sublime, Nietzsche, Freud.

"Mas dize também isto, ó singular forasteiro, quanto precisou sofrer este povo para poder tornar-se tão belo?"

Nietzsche, O nascimento da tragédia (1872/1992, p. 144).

No presente artigo, pretendemos desenvolver a ideia de que a experiência do belo inclui a dimensão da dor, quando levamos em consideração as obras de Nietzsche e de Freud.

Em Nietzsche, a via a ser percorrida para que haja a passagem do niilismo passivo para o niilismo ativo é a experiência do sublime, desenvolvida em $O$ nascimento da tragédia (1872/1992) como aquela que pode transformar o horror e a náusea da existência humana em arte. A força de Dionísios substitui a disposição ascética, negadora da vontade, característica da realidade cotidiana, pelo esquecimento inerente ao êxtase do estado dionisíaco. A realidade cotidiana seria marcada, segundo o filósofo, pelo aspecto horroroso e absurdo do ser, uma realidade da qual se tem nojo, e da qual só se pode ser salvo pela arte, pois só ela tem o poder de transformar aqueles pensamentos enojados sobre o horror e o absurdo da existência em representações com as quais é possível viver: são elas o sublime, enquanto domesticação artística do horrível, e o cômico, enquanto descarga artística da náusea do absurdo (Nietzsche, 1872/1992, p. 56).

O nascimento da tragédia indica como a verdade, para a cultura grega, encontra-se na força dionisíaca, força de uma exultação que coloca o sujeito sob o efeito de certas

\footnotetext{
1 Apoio financeiro: Ministério da Ciência, Tecnologia e Inovação - Conselho Nacional de Desenvolvimento Científico e Tecnológico. Bolsa de produtividade.

* Autora correspondente: mariaisabelfortes@gmail.com
}

“disposições de ânimo e cognições” (Nietzsche, 1872/1992, p. 58) que o transformam e o renovam.

Nessa perspectiva, o trágico proporia o fim do consolo metafísico da existência. Não mais a "serena jovialidade helênica" do homem teórico, que traz consigo um senil e improdutivo prazer na existência, mas sim a "sabedoria do sofrimento" encarnada pelo espírito dionisíaco.

Deste modo, Nietzsche (1872/1992) denuncia a racionalidade socrática, liberando o pensamento da tradição da metafísica e apresentando o sublime e a arte como possibilidades transformadoras. A tradição socrática é por esta via abalada, e o sinal disso é que o homem moderno já pressente os limites deste conhecimento, afirmando que "uma cultura edificada sobre o princípio da ciência tem de vir abaixo", já que ele mesmo percebe que neste princípio não há prazer nem força, fazendo dele, no fundo, "um bibliotecário e um revisor miseravelmente cego devido à poeira dos livros e aos erros de impressão" (Nietzsche, 1872/1992, p. 112).

O pensamento nietzschiano, dessa forma, busca romper com a metafísica, inaugurando uma nova imagem do pensamento (Deleuze, 1962), na qual a questão filosófica por excelência não é mais o ser, mas o valor. A pergunta não é mais "o que uma coisa é?", mas quais os valores que se ligam a essa coisa. Não se trata, aqui, do sujeito transcendental da metafísica, mas se institui um pensamento da imanência. A genealogia introduz na filosofia o sentido e o valor; a genealogia avalia (Deleuze, 1962). A visão nietzschiana, neste sentido, libera a potência do pensamento, indo contra uma concepção representativa da linguagem e retirando do pensamento a ideia de consciência e a ilusão de interioridade. Constitui-se, portanto, em um pensamento sobre o fora, que o libera da interioridade que estrutura a linguagem como representação. Nesta perspectiva, o pensamento começa fora e não na consciência, consistindo, portanto, em um pensamento da força e não da representação. É a exterioridade como o jogo das forças 
que atravessam e inscrevem o homem e o pensamento em um campo de imanência.

Foucault (1966) analisa o pensamento que se coloca fora de toda subjetividade, com seus limites aparecendo a partir do exterior. Nesse pensamento, o sujeito desaparece, não havendo qualquer interioridade, mas uma pura dispersão, sem que a linguagem esteja referida a um discurso que lhe seja preexistente. A linguagem não é mais discurso e comunicação de um sentido, mas estabelece-se em seu estado bruto, pura exterioridade desdobrada. Nessa nova concepção filosófica do pensamento, que se opõe à visão tradicional da metafísica, há um contínuo deslizamento da linguagem que é anterior a qualquer palavra. É o pensamento do fora que se situa em um lugar diferenciado em relação à interioridade da nossa reflexão filosófica e à positividade do nosso saber.

Foucault cita alguns autores como aqueles que inauguraram a experiência do fora, apresentando-os a partir dos conceitos centrais de suas respectivas obras. Assim, a atração em Blanchot, o desejo em Sade, a força em Nietzsche, a materialidade do pensamento em Artaud ou a transgressão em Bataille abriram um novo campo de pensabilidade para a filosofia (Foucault, 1966).

Consideramos pertinente refletir, para a questão que está sendo trabalhada no presente artigo, sobre a estética proposta pelo pensamento do fora, na medida em que estes escritores, segundo Foucault, testemunhariam uma experiência da linguagem em que não há mais a separação entre interior e exterior. Tal experiência, de certo modo, se contrapõe também à separação entre o belo e o horror, pois, por não haver a interiorização do ser, não haveria como expelir o horror para se construir o belo. A experiência do "fora", como já foi dito, se desdobra na forma de atração, como se fosse aventura e desejo do que pode existir para além do que pensamos existir. Não seria uma atração por algo, e sim o fato de nos sentirmos atraídos pela abertura, o que Foucault chama de uma "atração negligente": uma porta que baila, o aceno de uma mulher na janela, o sorriso do guardião sobre um umbral ilícito, um olhar voltado à morte (Foucault, 1966, pp. 523-546).

Assim, o que podemos considerar o espírito da experiência do "fora", ao apresentar uma nova imagem para o pensamento e, ao mesmo tempo, expondo o declínio da tradição metafísica, Nietzsche propõe o renascimento do trágico. Vale, aqui, diferenciar o lugar dado ao sofrimento na visão metafísica daquele por ele ocupado na perspectiva do trágico. Percebe-se aí uma espécie de oposição entre o sofrimento e a visão metafísica, aproximando-se esta mais de uma "felicidade de existir" (Nietzsche, 1872/1992, p. 95) do que da dor de existir. A metafísica, como uma forma de pensamento que se construiu a partir de categorias universais, se furta ao devir, propondo a estabilidade do ser, enquanto o trágico afirma o devir. Ao querer a estabilidade e a permanência das coisas, ao dizer não ao devir, a metafísica afasta-se da dor, que no fundo é a dor por não haver a permanência do ser. Trata-se de uma visão apaziguadora do horror da existência, que vê o homem como um ser sereno e simples inclinado para uma "felicidade de existir"
(Nietzsche, 1872/1992). É o homem teórico regulado pelos princípios da ciência, respondendo às razões maiores desta última, ou seja, à razão universal e à estabilidade do ser. Em contrapartida, o renascimento do trágico propõe uma cultura que se revela jubilosa ao se debruçar sobre a dor de existir.

No entanto, é importante frisar que, longe de fazer uma apologia à dor, de fixar-se na dor, o trágico transmuta a dor em alegria. A relação com o trágico não se apresenta exclusivamente como dor, mas também como júbilo, êxtase, exaltação. Como comenta Machado (1997), Assim falou Zaratustra (Nietzsche, 1883/1977) é uma afirmação jubilatória da existência, o que pode ser constatado no encontro do pastor com a serpente que se dá na parte "Da visão e do enigma". Nesse trecho, encontramos o pastor prestes a morder a serpente, contorcendo-se de náusea, ódio, asco e horror. Após morder a cabeça da serpente, ele a cospe para bem longe, e Zaratustra conclui: "Não mais pastor, não mais homem - um ser transformado, translumbrado, que ria! Nunca até aqui, na terra, riu alguém como ele ria!" (Nietzsche, 1883/1977, p. 168).

Desse modo, se a tragédia encena a dor, não é com o fim de cultuá-la, mas sim para afirmar a vida em sua diversidade. Na laceração de Dionísios encontra-se também o máximo de prazer. Por um lado, Dionísios expressa o sofrimento da individuação, por outro, reintegra-se depois no prazer do ser universal (Deleuze, 1962), tornando o homem superior ao mesmo tempo muito mais feliz e muito mais infeliz. Se Dionísios aspira ao infinito, revela com essa aspiração o construir e o desconstruir da individuação "como eflúvio de um arquiprazer" (Nietzsche, 1872/1992, p. 142). O êxtase do estado dionisíaco aniquila as barreiras da existência, retirando o indivíduo da realidade cotidiana e transportando-o para a realidade dionisíaca.

Segundo Kaufmann (1968), Dionísios é o símbolo grego representante do período pré-cristão, utilizado por Nietzsche para fazer oposição ao Cristo crucificado. Em Nietzsche (1872/1992), Dionísios expressa este aspecto de se debruçar sobre o sofrimento para pôr em cena a alegria trágica. Este aspecto, no entanto, é muito mais acentuado nos últimos trabalhos de Nietzsche, como em Ecce Homo (1908/1968), no qual Dionísios deixa de ser o espírito de uma paixão irrestrita para se tornar o símbolo por excelência "da afirmação da vida com todo o seu sofrimento e seu terror" (Nietzsche, 1908/1968, p. 665). O homem trágico afirma mesmo o mais cruel sofrimento, e por isso mesmo não se alia aos pessimistas.

Com efeito, a tragédia seria um antídoto contra o pessimismo de Sileno, sábio que disse que o bem supremo seria não ter nascido e, uma vez tendo nascido, que o melhor seria morrer o quanto antes, já que viver só traz dor (Machado, 1997, p. 132). A visão trágica, ao contrário, indica que dor não é sinônimo de tristeza, podendo haver alegria na dor. Esta alegria nunca é da ordem de uma resignação, já que o trágico não traz uma solução moral para a dor:

de onde deriva esse traço, em si enigmático, de que o sofrer no destino do herói, as mais dolorosas 
superações, as mais torturantes contradições dos motivos, em suma, a exemplificação daquela sabedoria de Sileno ou, expresso em termos estéticos, o feio e o desarmônico sejam, em tão incontáveis formas, com tanta predileção, representados sempre de novo, e precisamente na idade mais viçosa e juvenil de um povo, se justo nisso tudo não se percebesse um prazer superior? (Nietzsche, 1872/1992, p. 140).

O mito trágico, com a imagem do herói sofredor, transfigura a vida. Nesse sentido, o feio e o desarmônico podem suscitar um prazer estético, sendo aí que reside o segredo do sublime, conforme já dito. O prazer que a tragédia produz é similar à sensação prazerosa da dissonância na música, tendo ambas as artes o poder dionisíaco em sua matriz, revelando "o seu prazer primordial percebido inclusive na dor" (Nietzsche, 1872/1992, p. 141):

Música e mito trágico são de igual maneira expressão da aptidão dionisíaca de um povo e inseparáveis uma do outro . . a ambos transfiguram uma região em cujos prazenteiros acordes se perdem encantadoramente tanto a dissonância como a imagem terrível do mundo; ambos jogam com o espinho do desprazer ... ambos justificam com tal jogo a própria existência do "pior dos mundos" (Nietzsche, 1872/1992, p. 143).

Portanto, não é função da tragédia nos acalmar diante dos horrores da existência; ela não é apaziguadora, mas tonificante, operando a transmutação do sofrimento em alegria. A tragédia acontece quando há uma irrupção de Dionísios, com todo o seu poder perturbador e renovador, nas belas formas de Apolo. As potências dionisíacas não calam o desejo, mas, ao contrário, trazem-no à tona, causando um imenso ruído na busca apolínea de harmonia. Como vimos, o trágico é a estética presente no desarmônico, no feio, no dissonante. O trágico não recusa o feio, mas vê nele um brilho. Se o dionisíaco não é transformado em arte, ele se torna loucura desenfreada, pura potência de dissolução.

Afirmar o sofrimento, indicar que sofrer não é um aspecto ruim da vida, é mostrar que a dor é imanente ao nosso mundo. Na dor podemos encontrar um caminho para a criação, senão, como entender a frase com que Nietzsche finaliza O nascimento da tragédia (1872/1992)? "Mas dize também isto, ó singular forasteiro, quanto precisou sofrer este povo para poder tornar-se tão belo?” (p. 144).

Neste ponto, é importante ressaltar que a diferença entre a tragédia e o drama é que a primeira não cristaliza a dor como o segundo. A dor dramática é estanque, congelada, intransponível. Observa-se que a tragédia começa a perder seu lugar na cena histórica justamente quando surge o drama como um conflito íntimo, no qual o sofrimento é interiorizado, concebido como uma forma de castigo que justifica a vida, sendo o drama uma forma de usar o sofrimento para repreender a vida, para mostrar o quanto ela é negativa. O drama narra um conflito onde a dor é interiorizada, enquanto na tragédia está presente o sentido ativo e exteriorizado da dor. Como já mencionado, enquanto a interiorização é constitutiva do pensamento representativo, a forma exteriorizada do pensamento característica da tragédia marca esta nova figuração do pensamento inaugurada por Nietzsche: um pensamento por imagens e não por representação, um pensamento da força e não do ser, um pensamento que tem início no fora e não no interior da consciência. É neste novo território conceitual que podemos compreender a tragédia e seu sentido ativo para a dor, seu sentido externo, diferente do sentido passivo interiorizado da dor na sua forma dramática, no qual a dor que se interioriza torna-se reativa. No sentido ativo da dor, esta não é um argumento contra a vida, mas um fator que torna a vida excitante, "um argumento em seu favor" (Deleuze, 1962, p. 149).

Em Nietzsche (1872/1992), aprendemos que o renascimento do trágico é a via por excelência para combater o niilismo passivo que impera na cultura moderna. Nesse sentido, o renascimento da tragédia liberaria o homem desse tipo de pessimismo à medida que a cultura europeia possa se tornar cada vez mais grega e menos cristã, isto é, conforme possa afirmar o sofrimento trágico que paradoxalmente é um sofrimento alegre.

A liberação do pessimismo só pode ocorrer com a passagem do niilismo passivo para o ativo. O primeiro se caracteriza por uma forma reativa, na qual impera a negação e a desvalorização da vida em nome de uma vida superior. Diante do fato de que a vida passa e de que o instante não retrocede, o niilista passivo se paralisa, ficando sufocado e nauseado. Esse é o niilismo criado pelo platonismo e pelo cristianismo, que desvalorizam esta vida pregando outra, melhor e mais verdadeira, fundamentando-se na convicção de que por esta vida ser horrível é necessário almejar outra, alhures e mais perfeita.

O que faz a vida ser uma fonte constante de sofrimento é principalmente o desconsolo quanto à passagem do tempo. A fonte do sofrimento advém da passagem do tempo, do fato de que o instante não volta e que a vida não é eterna. Não querer a passagem do tempo, ou querer a sua estagnação ou a sua eternidade, é o que marca o niilismo passivo.

A revolta contra a passagem do tempo é analisada por Freud em um ensaio escrito em 1916, intitulado "Sobre a transitoriedade". Freud relata um passeio que fazia com um amigo poeta que, embora admirasse a beleza do cenário, não conseguia extrair disso qualquer alegria. Desconsolava-o que o encanto daquele cenário estava necessariamente fadado à extinção, quando sobreviesse o inverno. Para o poeta, a beleza deveria ser eterna, e sua transitoriedade era para ele algo perturbador.

Para Freud, ao contrário, a finitude da beleza aumentava o seu valor, não interferindo em nada sua transitoriedade na fruição da mesma: "Uma flor que dura apenas uma noite nem por isso parece ser menos bela" (Freud, 1916/1974, p. 317). 
Para Freud, a fruição do belo era perturbada, no caso desse amigo, pela revolta contra sua extinção, pela dor insuportável da perda. A percepção da transitoriedade da beleza gerou nele uma antecipação do luto pela morte dessa mesma beleza, provocando-lhe um desconsolo que impedia a fruição do cenário presente. Segundo França (1997), a melancolia do poeta fazia que ele recuasse "diante da experiência penosa do luto" (p. 158), ficando desse modo, incapaz de usufruir do belo:

Diante do horror de viver a dor da perda, o poeta dissocia o que há de horrível no Belo, demonstrando a impossibilidade, diante disto, de ter acesso à dimensão da estética do desejo. O tempo no Belo é não antecipado, surpreendente e percebido na efemeridade do instante. (França, 1997, p. 158)

Este é um modo de funcionamento similar, a nosso ver, ao niilismo passivo, que não aceita que a vida não seja eterna, não admitindo a passagem do tempo e a finitude da vida. O pessimista, como vimos com Sileno, é aquele que pensa que, já que a morte é certa, melhor seria nem ter nascido; rechaça a vida por esta ser finita. O poeta amigo de Freud também sentia que a transitoriedade da beleza impedia a sua fruição, sendo marcado por uma "renúncia permanente porque aquilo que era precioso revelou-se não ser eterno" (Freud, 1916/1974, p. 319).

É importante, neste ponto, avaliarmos as diferenças entre as noções de sublime e de belo. No presente artigo, não estamos diferenciando com precisão os dois termos, tratando-os como sinônimos. Entretanto, vale notar que há uma diferença importante entre as duas noções. Burke, em Uma investigação filosófica sobre a origem de nossas ideias do sublime e do belo (1757/1993), circunscreve o sublime ao registro da dor, isto é, daquilo que está próximo do horror, produzindo, portanto, a "mais forte emoção de que o espírito é capaz" (Burke, 1757/1993, p. 48). O sublime rompe com um imaginário já estabelecido e, longe do que prega o senso comum ao dizer que o ser humano quer distância do sofrimento, revela uma inclinação do humano para tudo aquilo que causa uma dor muito forte:

Tudo que seja de algum modo capaz de incitar as ideias de dor e de perigo, isto é, tudo que seja de alguma maneira terrível ou relacionado a objetos terríveis ou atua de um modo análogo ao terror, constitui uma fonte do sublime, isto é, produz a mais forte emoção que o espírito é capaz. Digo a mais forte emoção, porque estou convencido de que as ideias de dor são muito mais poderosas do que aquelas que provêm do prazer. (Burke, 1757/1993, p. 48)

Já o belo não apresenta qualquer caráter disruptivo nem ameaçador. Para Burke, a estética do belo é apaziguadora, respondendo às expectativas sociais já estabelecidas, não provocando rupturas no imaginário ideativo da cultu$\mathrm{ra}$, estando em perfeita harmonia com as formas traçadas pelos ideais da cultura. Com efeito, enquanto o sublime seria encontrado mais na dimensão da dor, o belo estaria mais circunscrito ao prazer.

Se, por um lado, o belo produz um prazer que é da ordem da estesia, por outro, não se expressaria por uma experiência de intensidade, de êxtase, que provocaria, por sua vez, uma espécie de disrupção da organização egoica. Nesta perspectiva, subentende-se a presença de acordes monotônicos no belo, cuja harmonia não causaria constrangimentos, mas também não conduziria o sujeito a qualquer abertura para a exultação.

Uma frase de Goethe citada por Freud indica também este caráter de monotonia inerente ao belo: "Nada é mais difícil de suportar do que uma sucessão de dias belos (Goethe, 1810, citado por Freud, 1930/1974, p. 95). Já o sublime manifesta-se como uma experiência de intensidade, ligando-se o horror ao deleite que este pode provocar em certas circunstâncias, sem que se busque um distanciamento da dor (Burke, 1757/1993, p. 54).

É importante lembrar que a ideia do sublime e o conceito de sublimação são da maior importância nas teorizações psicanalíticas. Esse conceito foi formulado pela primeira vez por Freud, em 1908, em A moral sexual "civilizada" e a doença nervosa moderna, no qual se atesta que as grandes produções do espírito humano se apoiam em uma "dessexualização" das pulsões, que permitiria as produções artísticas e científicas:

Esse instinto coloca à disposição da atividade civilizada uma extraordinária quantidade de energia, em virtude de uma singular e marcante característica: sua capacidade de deslocar seus objetivos sem restringir consideravelmente a sua intensidade. A essa capacidade de trocar seu objetivo sexual original por outro, não mais sexual, mas psiquicamente relacionado com o primeiro, chama-se capacidade de sublimação. (Freud, 1908/1974, p. 193)

Nesse primeiro momento, a sublimação consistiu na capacidade de trocar um alvo sexual por outro, não sexual, mas sem que ocorra nessa troca de alvo uma mudança do objeto da pulsão. Poucos anos depois, em Uma lembrança infantil de Leonardo da Vinci (Freud, 1910/1974), o conceito de sublimação é reformulado, passando a significar um processo que inclui não só uma mudança do alvo da pulsão, como também de objeto, que será considerado conforme o seu valor social. Nessa outra visão freudiana, a sublimação é concebida como uma transformação direta da pulsão sexual em uma produção do espírito, a segunda não constituindo uma operação que exclui a primeira. Ocorre, aqui, a mudança tanto do alvo quanto do objeto da pulsão (Birman, 1988, p. 72).

Segundo França (1997), a ligação da sublimação com o horror é o que leva à "outra satisfação", entendendo-se como tal, nesse segundo tempo da elaboração teórica do conceito, como o destino por excelência da sublimação, isto é, "como uma satisfação implicada na mudança de objeto e do seu alvo, o que não quer dizer que o objeto sexual 
desapareça. Pelo contrário, o objeto sexual é ressaltado" (p. 191).

Com efeito, essa segunda compreensão da sublimação é a que mais nos interessa no presente artigo, pois se trata mais efetivamente da sublimação como um ato de criação, já que implica o encontro de um novo objeto para a pulsão. Aqui, aquela passa a ser uma forma de expressão valorizada na cultura, deixando de ser uma forma de defesa, para ser concebida como estesia, como produção estética:

a outra satisfação própria da sublimação é mediadora dos laços sociais, na medida em que "o objeto elevado à dignidade da Coisa" não se torna necessariamente sublime, ao contrário, sua função é de alguma forma desvelada como uma potência insistente e cruel. (p. 191)

A proximidade do ato criativo com a dor é também trabalhada por Kristeva (1989) em Sol negro: depressão e melancolia, onde a autora associa o traço de melancolia a vários artistas, mostrando como a relação profunda deles com a dor é o terreno propício para o processo criativo. Holbein, Nerval, Dostoievsky, Duras e Lispector testemunham essa passagem do sofrimento para a arte, o processo que permite transformar o horror em ato criativo, "a linguagem poética que acompanha o eclipse do sujeito melancólico" (p. 139).

Entretanto, é importante observar que, se a sublimação se oferece, como um canal que pode barrar o intenso sofrimento, ela pode também fazer emergir ímpetos mortíferos. Carvalho (2010) faz uma análise importante sobre como a sublimação pode ser tanto benéfica quanto nociva, podendo representar "um perigo constante de um salto para uma morte mortífera que aponta a precariedade da rede simbólica" (p. 525). Os limites da sublimação se estabeleceriam, segundo a autora, na tensão entre "a movimentação pulsional da escrita e o trabalho das forças defensivas que se the contrapõem" (p. 525). O recurso à sublimação pode propiciar, sem conseguir evitar, a irrupção pulsional excessiva que abala a organização psíquica, como pode ser atestado pelas obras de Silvia Plath, David Foster Wallace, Anne Sexton, Ana Cristina César, dentre outros, cujas produções literárias não impediram que cometessem o suicídio (Carvalho, 2001, 2010).

A proximidade da experiência estética com o assombro e a inquietação foi também analisada por Freud em O Moisés de Michelangelo (1914), em qual ele relata sua experiência pessoal de sideração e abalo diante da obra de Michelangelo. Freud narra ter subido inúmeras vezes os íngremes degraus que levam à igreja de San Pietro in Vincoli onde se encontra a estátua de mármore. Lá, ficava horas sentado em um banco, tentando decifrar a "inescrutável estátua", tentando suportar "o irado desprezo do olhar do herói" (p. 255). A inquietação que acometia Freud era o fato de não conseguir interpretar (ele, o mestre da interpretação) a intenção do artista através da obra de arte. A posição de enigma e dúvida acossava o homem de saber, o mestre, o escritor de ensaios teóricos. A dimensão de mistério só aumentava a admiração que a obra lhe provocava:
Isto me levou a reconhecer o fato - um paradoxo evidente - de que precisamente algumas das maiores e mais poderosas criações de arte constituem enigmas ainda não resolvidos pela nossa compreensão. Sentimo-nos cheios de admiração reverente por elas e as admiramos, mas somos incapazes de dizer o que representam para nós. (Freud, 1914/1974, p. 253)

Tomado por uma espécie de "perplexidade intelectual", Freud avalia inúmeras interpretações já realizadas sobre a estátua, constatando que os conhecedores da obra também não chegaram a capturar o enigma de sua magnitude. Segundo Schneider, diante dessa magnífica obra de Michelangelo, Freud se sente em uma posição de vulnerabilidade que o inquieta e o faz retornar tantas vezes à igreja. Diante do olhar enfurecido de Moisés, o psicanalista sente-se impelido a dar uma resposta, a devolver a esse olhar acusador uma compreensão intelectual que ofereça algum reasseguramento (Schneider, 1978). Ele descreve de maneira eloquente, neste ensaio, o quanto queria poder oferecer uma interpretação à estátua, mas como ela lhe escapava, só se apresentando a ele como um grande enigma. A intensidade que provém da obra e a incapacidade para capturá-la totalmente pelo intelecto promoveram uma experiência de dor. Portanto, Freud oferece nesse ensaio um testemunho pessoal de uma experiência subjetiva na qual se entrelaçam a dor e o belo.

\section{Considerações finais}

Buscamos demonstrar a proximidade da experiência estética com as dimensões da dor e do horror. Esse amalgamento entre as duas experiências, segundo Freud, pode advir tanto do fato de a beleza ser, já de antemão, marcada por seu desvanecimento, o que provoca dor como um prenúncio antecipado da perda, quanto porque o belo gera aflição, ao não ser capturável pela compreensão, ao não encontrarmos palavras para explicar a comoção que nos acomete. No percurso que buscamos traçar, costuramos o pensamento freudiano com alguns elementos das obras de Nietzsche e de Foucault que tratam da questão da arte. Em Nietzsche, vimos como o belo precisa incluir necessariamente o trágico, o feio, o desarmônico, já que estes elementos fazem parte da vida, e negá-los seria excluir a própria vida. Por outro lado, a experiência do sublime é o que permite transformar o horror em arte, só ela tendo o poder de deslocar a náusea da existência em representações com as quais é possível viver. Em Foucault, apontamos a abertura que a produção estética promove para o pensamento do fora, pelo qual uma experiência não se inclui no mundo da representação, mas se abre para a exterioridade. A "atração" constitui uma posição do sujeito, muito mais do que a ânsia pelo mundo dos objetos. Nos três autores, Freud, Nietzsche e Foucault, encontramos elementos importantes sobre a necessária junção da arte com a dor. Dor incômoda e forasteira, mas com a qual é preciso conviver se queremos vislumbrar a beleza. 


\section{The extraneous pain and the transitory beautiful: Nietzschean and Freudian perspective}

Abstract: This paper develops the idea that the experience of the Beautiful necessarily implies the dimension of pain, out of the works of Freud and Nietzsche. In the first author we investigate the pain of anticipated mourning related to the transience of beauty, the importance of the concept of sublimation and the analysis of Freud's disturbing experience before the statue of Moses by Michelangelo. In the second author, we develop the main ideas of the bookThe Birth of Tragedy in order to demonstrate how art has the power to transform emptiness in vitality, as the sublime displaces the nausea and horror of existence into livable representations. The tragic assumes that the aesthetics underlies the disharmonious, the ugly and the dissonant, being thus an aesthetic path in which the beautiful necessarily includes the dimensions of pain and horror.

Keywords: pain, beautiful, sublime, Nietzsche, Freud.

\section{La douleur étrangère et le beau passager: perspectives nietzschéenne et freudienne}

Résumé: L'article développe l'idée que l'expérience du Beau inclut nécessairement la dimension de la douleur, à partir de l'œuvre de Freud et Nietzsche. Chez Freud, on étudie la douleur de l'anticipation du deuil face à la fugacité de la beauté, l'importance de la notion de sublimation et l'analyse de l'expérience troublante du auteur devant la statue de Moïse, de Michel-Ange. Chez Nietzsche, on développe les idées principales du livre La Naissance de la tragédie pour démontrer comment l'art a le pouvoir de transformer le vide en vitalité, car le sublime convertit la nausée et l'horreur de l'existence en représentations avec lesquelles il est possible de vivre. Pour cela, le tragique suppose que l'esthétique est sous-jacente au disharmonieux, au laid, au dissonant, étant donc une voie esthétique à travers laquelle le beau englobe nécessairement les dimensions de la douleur et de l'horreur.

Mots-clés: douleur, beau, sublime, Nietzsche, Freud.

\section{El dolor extraño y el bello pasajero: perspectivas nietzscheana y freudiana}

Resumen: Este artículo desarrolla la idea de que la experiencia del Bello incluye necesariamente la dimensión del dolor, a partir de las obras de Freud y Nietzsche. En el primer autor, investigamos el dolor de la anticipación del luto frente a la transitoriedad de la belleza, la importancia del concepto de la sublimación y el análisis de la experiencia perturbadora de Freud frente a la estatua de Moisés, de Miguel Ángel. En el segundo autor, presentamos las ideas principales del libro El Nacimiento de la Tragedia para demostrar cómo el arte tiene el poder de transformar el vacío en vitalidad, pues el sublime desplaza la náusea y el horror de la existencia en representaciones con las cuales es posible vivir. Por lo tanto, es defendido que el trágico supone una estética próxima del feo y del disonante, haciendo del bello una experiencia que incluye las dimensiones del dolor y del horror.

Palabras clave: dolor, bello, sublime, Nietzsche, Freud.

\section{Referências}

Burke, E. (1993). Uma investigação filosófica sobre a origem de nossas ideias do sublime e do belo. São Paulo, SP: Papirus. (Trabalho original publicado em 1757).

Carvalho, A. C. (2001). Pulsão e simbolização: limites da escrita. In G. Bartucci (Org.) Psicanálise, literatura e estéticas da subjetivação (pp. 251-285). Rio de Janeiro, RJ: Imago.

Carvalho, A. C. (2010). A toxidez da escrita como um destino da sublimação em David Foster Wallace. Psicologia USP, 21(3), 513-530.

Deleuze, G. (1962). Nietzsche et la philosophie. Paris, França: PUF.

Foucault, M. (1966). La pensée du dehors. Critique, 229.

França, M. I. (1997). Psicanálise, estética e ética do desejo. São Paulo, SP: Perspectiva.
Freud, S. (1974). Moral sexual civilizada e doença nervosa moderna. In S. Freud, Obras completas. Rio de Janeiro, RJ: Imago. (Trabalho original publicado em 1908).

Freud, S. (1974). Leonardo Da Vinci e uma lembrança da sua infância. In S. Freud, Obras completas. Rio de Janeiro, RJ: Imago. (Trabalho original publicado em 1910).

Freud, S. (1974). O Moisés de Michelangelo. In S. Freud, Obras completas. Rio de Janeiro, RJ: Imago. (Trabalho original publicado em 1914).

Freud, S. (1974). Sobre a transitoriedade. In S. Freud, Obras completas. Rio de Janeiro, RJ: Imago. (Trabalho original publicado em 1916).

Freud, S. (1974). O mal-estar na civilização. In S. Freud, Obras completas. Rio de Janeiro, RJ: Imago. (Trabalho original publicado em 1930). 
Kaufmann, W. (1968). Basic Writings of Nietzsche. New York, NY: The Modern Library.

Kaufmann, W. (1974). Nietzsche: philosopher, psychologist, antichrist. Princeton, NJ: Princeton University Press.

Kristeva, J. (1989). Sol negro - depressão e melancolia. Rio de Janeiro, RJ: Rocco.

Machado, R. (1997). Zaratustra: tragédia nietzschiana. Rio de Janeiro, RJ: Jorge Zahar.

Nietzsche, F. (1977). Assim falou Zaratustra: um livro para todos e para ninguém. Rio de Janeiro, RJ: Civilização Brasileira. (Trabalho original publicado em 1883).
Nietzsche, F. (1992). O nascimento da tragédia ou Helenismo e pessimismo. São Paulo, SP: Companhia das Letras. (Trabalho original publicado em 1872).

Nietzsche, F. (1968). Ecce homo. In W. Kaufmann (Ed.), Basic Writings of Nietzsche. Nova York, NY: The Modern Library. (Trabalho original publicado em 1908). Schneider, M. (1978). La séduction et l'excitation consentie, In Topique - Revue freudienne: Réperes, 21(2), pp. 105127.

Recebido: $15 / 04 / 2014$

Revisado: 19/10/2014

Aceito: 10/06/2015 